\title{
Turkish Journal of Chemistry'nin Bibliyometrik Analizi
}

\author{
Bibliometric Analysis of Turkish Journal of Chemistry
}

\section{Hatice Gülşen BíRíNCi}

\section{Öz}

Bu makalede 1995 yılından beri Science Citation Index (SCI) ve Chemical Abstracts tarafindan indekslenen Turkish Journal of Chemistry (TJC) bibliyometrik açıdan ele alınarak, bu dergide 1995-2007 yılları arasında yayınlanan 861 makale incelenmiştir. Araştırmada cevap aranan sorular şunlardır: TJC'de en verimli yazarlar kimlerdir ve yazarlar arasındaki ilişki durumu nedir? TJC'de çok yazarlılık durumu nedir? TJC'ye katkıda bulunan yazarların kurumları nelerdir? TJC'de yayınlanan makaleler Bradford, Lotka, Price Yasası ve 80/20 Kuralı'na uymakta mıdır? TJC'de yazarların atıf yaptıkları kaynak türleri nelerdir? En sık atıf yapılan dergiler hangileridir? Yapılan atıflar gözönüne alıdığında Kimya alanındaki çekirdek dergiler hangileridir? TJC'de yayınlanan makalelerin aldıkları ortalama atıf sayısı nedir ve atıflarda yıllara göre bir artış söz konusu mudur? Journal Citation Reports (JCR)'da ve SCl'de TJC'nin yeri nedir? Yazarlara ve kurumlara özgü tekil sonuçlar, makalede açıklanmıştır. Diğer taraftan yazarların durumu, Price ve Lotka Yasası ve 80/20 Kuralı'na uymamaktadır., Öte yandan, TJC'de yapılan atıfların Bradford Yasası'na ve 80/20 Kuralı'na uyduğu saptanmıştır. Yazarlar ağ analizi ile incelendiğinde ise, beş ve daha fazla makale ile katkıda bulunan yazarların iki ayrı etkileşimli grup

*Uzman; Halil Inalcık Osmanlı Araştırmaları Merkezi, Bilkent Üniversitesi, (birinci@bilkent.edu.tr). 
oluşturduğu saptanmıştır. TJC'ye yapılan atıflar 1996 yılından beri istikrarlı bir atış göstermektedir.

Anahtar sözcükler: Turkish Journal of Chemistry, Bibliyometri, Ağ analizi

\section{Abstract}

This article dealing with the bibliometric analysis of 861 articles published between the years 1995-2007 of Turkish Journal of Chemistry which has been indexed by the Social Science Citation Index and Chemical Abstract since 1995. The following research questions have been discussed: Who are the most productive author? What is the relationship between the authors? What is the trend towards multiple authorships in TJC? What are the institutional affiliations of authors? Does the distribution of authors fit Bradford's, Lotka's and Price's Law and 80/20 Rule? Which types of sources get cited more often in articles? Which journals are the most cited? According to cited journals what are the core journals in chemistry? With regard to impact factor, what is the place of TJC in JCR and SCI?

The most productive authors are Sakıp Ali and Ihsan Çalış. Distribution of authors does not fit Bradford's, Lotka's and Price's Law and 80/20 Rule, but distirbution of citations fit Bradford and 80/20 Rule. Contributors affiliated with Hacettepe University, Ankara University, and Ataturk University. Journals received \%82 of all citations in the TJC. Turkish Journal of Chemistry, Journal of the American Chemical Society, Phytochemistry and Journal of Organic Chemistry were the most frequently cited journals. Number of references made to TJC has been growing consistently since 1996.

Keywords: Turkish Journal of Chemistry, Bibliometrics, Network analysis 


\section{Giriş}

Yayın hayatına İngilizce olarak 1976 yılında başlayan ve 1995 yılından beri Science Citation Index (SCl) tarafından indekslenen Turkish Journal of Chemistry (TJC), ülkemizde kimya alanında yayın yapan tek hakemli dergidir. Bu açıdan bibliyometrik incelemesi ülkemizdeki kimya biliminin ve literatürünün analiz edilmesi açısından son derece önemlidir.

Kimya alanında Türkiye'de ilk süreli yayın, 1933 yılında Türk Kimyagerler Cemiyeti tarafından çıkarılan "Kimya ve Sanayi" adlı dergidir. Turkish Journal of Chemistry (TJC) ise yayın hayatına 1976 yılında "Doğa Turkish Journal of Chemistry" adıyla başlamış, daha sonra Turkish Journal of Chemistry adını almış, 2002 yılına kadar üç ayda bir, 2002 yılından sonra ise iki ayda bir yayınlanmaya başlamıştır. Dergi, TÜBITAK tarafından hakemli ve Ingilizce olarak yayınlanmaktadır ve Science Citation Index ve Chemical Index tarafından 1995 yılından beri indekslenmektedir.

\section{Amaç}

Çalışmanın amacı TJC'de yer alan yayınların bibliyometrik özelliklerini ve SCl kapsamında disiplinlerarası kimya konusunda yer alan kimya dergileri içinde TJC'nin yerini incelemektir. Çalışmamızda cevap aranan sorular şunlardır:

- $\quad$ TJC'de en verimli yazarlar kimlerdir?

- Yazarlar arasında nasıl bir ilişki vardır?

- $\quad$ TJC'de çok yazarlılık durumu nedir? Yayınlanan makaleler ortalama kaç yazarlıdır?

- TJC'de yayın yapan yazarlar hangi kurumlarda çalışmaktadırlar?

- $\quad$ TJC'de yayınlanan makaleler Bradford Yasasina uyuyor mu?

- $\quad$ TJC'de yayınlanan makaleler Lotka Yasası'na uyuyor mu?

- TJC'de yayınlanan makaleler Price Yasası'na uyuyor mu?

- TJC'de yayınlanan makaleler 80/20 kuralına uyuyor mu? 
- $\quad$ TJC'deki makalelerin aldıkları ortalama atıf sayısı nedir?

- $\quad$ TJC'de makalelerin atıf yaptıkları kaynak türleri nelerdir?

- $\quad$ TJC'de en sık atıf yapılan dergiler hangileridir?

- $\quad$ TJC'de yayınlanan makalelerde en sık atıf yapılan dergilere göre, kimya alanındaki çekirdek dergiler hangileridir?

- $\quad$ TJC'ye yapılan atılların ülke, dergi ve yıllara göre dağııımı nasıldır?

- $\quad$ Science Citation Index'te TJC'nin yeri nedir?

- Journal Citation Reports'ta TJC'nin yeri nedir?

\section{Kapsam}

TJC Science Citation Index tarafından indekslenen disiplinlerarası kimya konu başlı̆̆ı altındaki 138 dergi, kimya mühendisliği alanında indekslenen 110 dergiden biridir. Çalışma, 1995-2007 yılları arasında TJC'de yayınlanan 868 adet yayını içermektedir.. Bunlardan 861 'i makaledir ve araştırmamızda incelenmiştir. Ayrıca bir eleştiri, bir biyografi, iki editoryal, üç düzeltme, yazısı bulunmaktadır.

\section{Yöntem}

TJC'deki yayınları inceleyebilmek amacıyla 1 Kasım 2007 tarihinde $\mathrm{SCl}$ veri tabanından çevrimiçi bir tarama yapılarak TJC'deki 868 adet yayına ilişkin veriler elde edilmiştir. Bu veriler içinde; yazar adları, yazar adresleri, makale isimleri, yayın dilleri, yayın yılları, doküman türleri, kaç yayına atıf yapıldığı ve kaç yayın tarafından atıf aldığı bilgisi yer almaktadır. Araştırmamızda elde edilen veriler, Excel ve bibliyometrik yazılımlardan Bibexcel ve Pajek kullanılarak değerlendirilmiş ve ağ analizi uygulanarak yazarlar ve kurumlar arasındaki ilişkiler ortaya çıkarılmaya çalışılmıştır.

\section{Bulgular}

1995-2007 yılları arasında TJC'de 861 makale yayınlanmıştır. 2002 yılı 113 makaleyle en çok makale yayınlanan yıl olmuştur (Bkz. Şekil 1). Bu artışta, derginin 2002 yılından itibaren iki ayda bir yayınlanmaya başlamasının etkisi bulunduğunu söylemek 
mümkündür. Dergi yılda 6 sayı çıkmaya başladığından bu yana, her yıl 88, her sayıda ise ortalama 14 makale yayınlamaktadır.

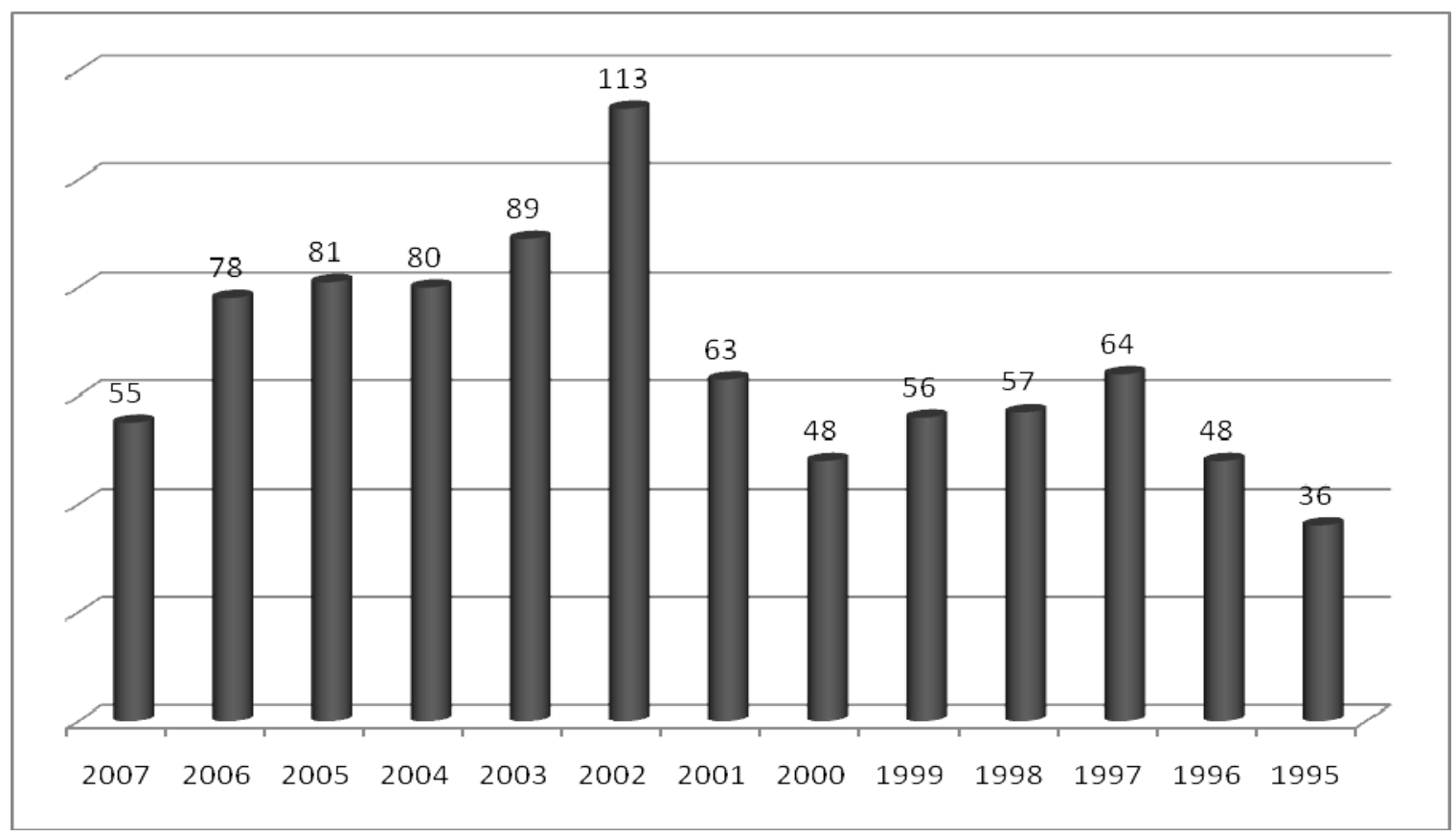

Şekil 1. Yıllara Göre Makale Sayıları

\section{Yazar}

Araştırma kapsamındaki yıllar arasında TJC'de yayınlanan 861 makale 1628 farklı yazar tarafından yazılmıştır. Yazarların 1148'i (\%70) TJC'ye birer makale ile katkıda bulunurken en çok katkı yapan yazarlar, 21 makale ile Sakıp Ali ve 16 makale ile İhsan Çalış olmuştur. TJC'de yayınlanan makalelerin 100'ü $(\% 11,6)$ tek yazarlıdır (Bkz. Şekil 2). Yazar sayısının en fazla olduğu iki makale 11'er yazarlı iken, makale başına düşen ortalama yazar sayısı 1,9'dur. Al (2005), bir yayının birden çok kişi tarafından kaleme alınmasının yayının niteliğini olumlu yönde etkileyecek bir unsur olduğunu, çünkü çok yazarlı yayınlar için hakemlik sürecinin makalenin ortaya çıkmasından daha önce yazarlar arasındaki iletişimle başladığını ve son ürün elde edilinceye kadar birçok kez farklı araştırmacılar tarafından gözden geçirilmesinin yayının daha iyi olmasına katkı sağlayacağını ifade etmektedir. 


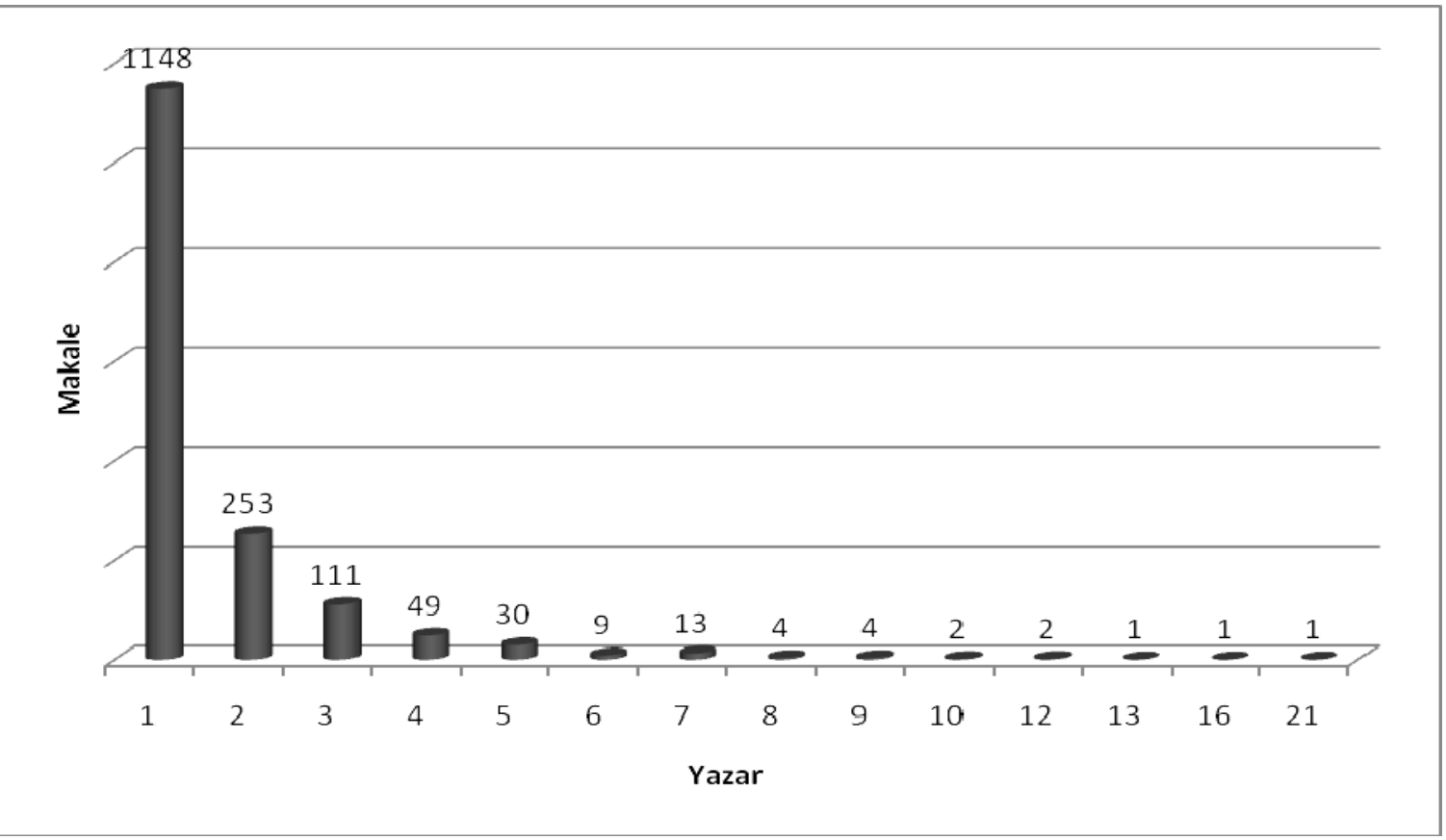

Şekil 2. Yazar ve Makale Sayıları

80/20 kuralı olarak da ifade edilen Pareto Yasası, ekonomi, demografi, bilgibilim gibi pek çok alanda kullanılmaktadır. Kütüphanecilik literatüründeki anlamını Egghe, (1986, s.55, aktaran; Yılmaz, 2005, s. 309) bir konuda yazılmış belli sayıdaki makaleye sahip dergiler, bir araştırma merkezinde belli bir sayıda yazı yazan yazarlar, bir metin içinde belli bir sayıda mevcut olan kelimeler ve bir kütüphanede belli bir sayıda ödünç alınan kitaplar olarak açıklar. 80/20 kuralı çerçevesinde makaleler ve yazarlar incelendiğinde, makalelerin \%72'sinin yazarların \%20'si tarafından yazıldığı anlaşılmaktadır. Hernekadar makalelerin $\% 72$ gibi büyük bir bölümünün az sayıda yazar tarafından yazıldığı görülmekte ise de, TJC'nin 80/20 kuralına uymadığı saptanmıştır.

Price Yasası "toplam dergi sayısının karekökü kadar dergi toplam makalelerin yarısını içermektedir" olarak formüle edilir (Egghe ve Rousseau, 1990, s. 362). Price Yasası TJC yazarlarına uyarlandığında, toplam yazar sayısı olan 1628'in karekökü kadar yani 40 yazarın 861 makalenin yarısını (430,5 makale) yazmasının beklendiği söylenebilir. Ancak yazarlar bu açıdan incelendiğinde, TJC'nin bu yasaya da uymadığı saptanmıştır. 
Lotka Yasası bir alanda, yazarların \%60'ının bir makale ile, \%15'inin 2 makale ile, \%7'sinin 3 makale ile katkıda bulunduğunu öngörürmektedir. (Rowlands, 2005, s.7). Lotka yasası çerçevesinde makaleler ve yazarlar incelendiğinde, TCJ'ye bir makale ile katkıda bulunanların yazarların \%70'ini, iki makale ile katkıda bulunanların \%15'ini, üç makale ile katkıda bulunanların $\% 7$ 'sini, dört makale ile katkıda bulunanların \%3'ünü, beş makale ile katkıda bulunanların ise \%2'sini oluşturduğu görülmektedir. TJC'nin bu yasaya da uymadığı anlaşılmaktadır.

1900-2000 yılları arasında kimya, matematik ve sosyoloji alanlarına ait üç farklı derginin ele alındığı çalışmada, makale başına yazar sayısındaki en yüksek artışın kimya alanında olduğu sonucuna ulaşılmıştır (Liu, 2003, aktaran; Al, 2005) Araştırmaya göre Journal of the American Chemical Society'de yayınlanan makalelerde 1900 yılında ortalama yazar sayısı 1,4 iken, 1950 yllında 2,4'e, 2000 yılında ise 4,3'e yükselmiştir. TJC'de ise makale başına düşen ortalama yazar sayısı 1,9'dur. Bu ortalamanın bir kimya dergisi için oldukça düşük olduğu, ve kimya alanındaki ortak yazarlılık göz önüne alındığında bu durumun dünyadaki eğilimden farklılık gösterdiği anlaşılmaktadır.

Sosyal ağ analizi etkileşimli gruplar arasındaki ilişkinin önemi varsayımına dayanmaktadır. Sosyal varlıkların arasındaki bağın ve bu bağın anlamının anlaşıması olarak da ifade edilebilir (Said ve diğerleri, 2008, s. 2177). Sosyal varlıklar birer aktör olarak tanımlanırlar ve bir çizgede birer dügüm olarak gösterilirler. Sosyal ağ analizi işte bu sosyal yapı içindeki kurumlar, kişiler, gruplar veya birbiriyle ilişki içinde olan her türden yapıyı analiz etmek için kullanılır.

Ortak yazarlılık ağ analizi yöntemiyle incelendiğinde tek bir makaleye katkıda bulunan yazar sayısının fazlalığı burada da göze çarpmaktadır (Bkz. Şekil 3). Ayrıca diğer yazarlardan bağımsız bir şekilde kendi aralarında çalışan yazarlar da, dairenin dışında kalmaktadır. Özellikle Pakistan ve Hindistan'dan katkıda bulunan bu araştırmacıların, Türkiye'deki üniversitelerle tek bir noktadan ilişki içinde olsalar bile, bağımsız olarak dairenin dışında kaldıkları ve kendi içlerinde çalışma yaptıkları görülmektedir. 
Yazarlar arasındaki ilişkiyi daha net bir analizle ortaya çıkarabilmek amacıyla beş ve daha fazla makale ile katkıda bulunan 54 yazarın arasındaki ilişki ayrıca incelenmiş, bu yazarların etkileşimli iki ayrı grup oluşturduğu görülmüştür ( $B k z$. Şekil 4). Bu etkileşimli iki gruptan küçük olan Pakistan adresli araştırmacılar küçük grubu, Türkiye ve yurtdışından araştırmacılar ise büyük grubu oluşturmaktadır.

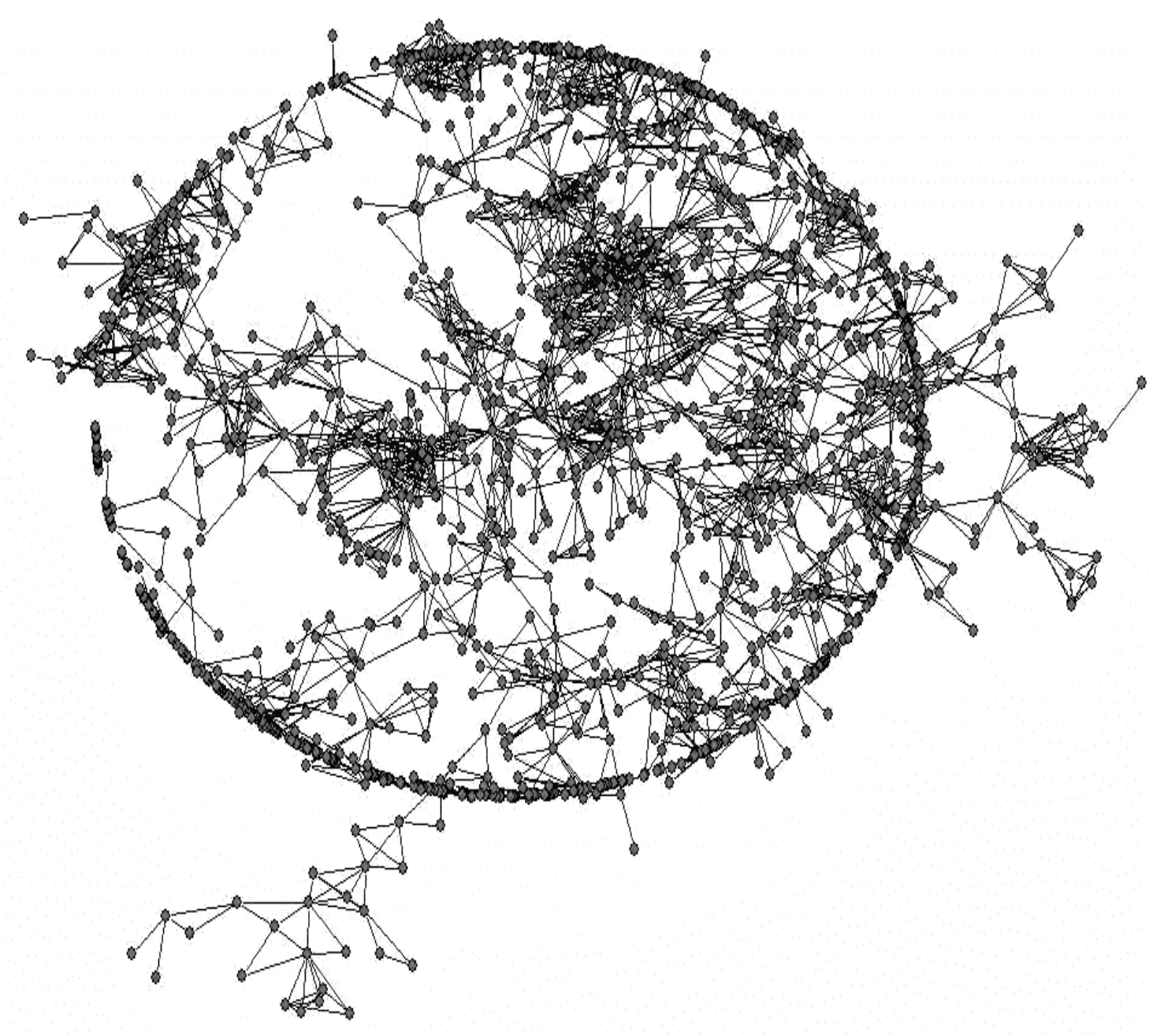

Şekil 3. Yazarlar Arasındaki İlişki 


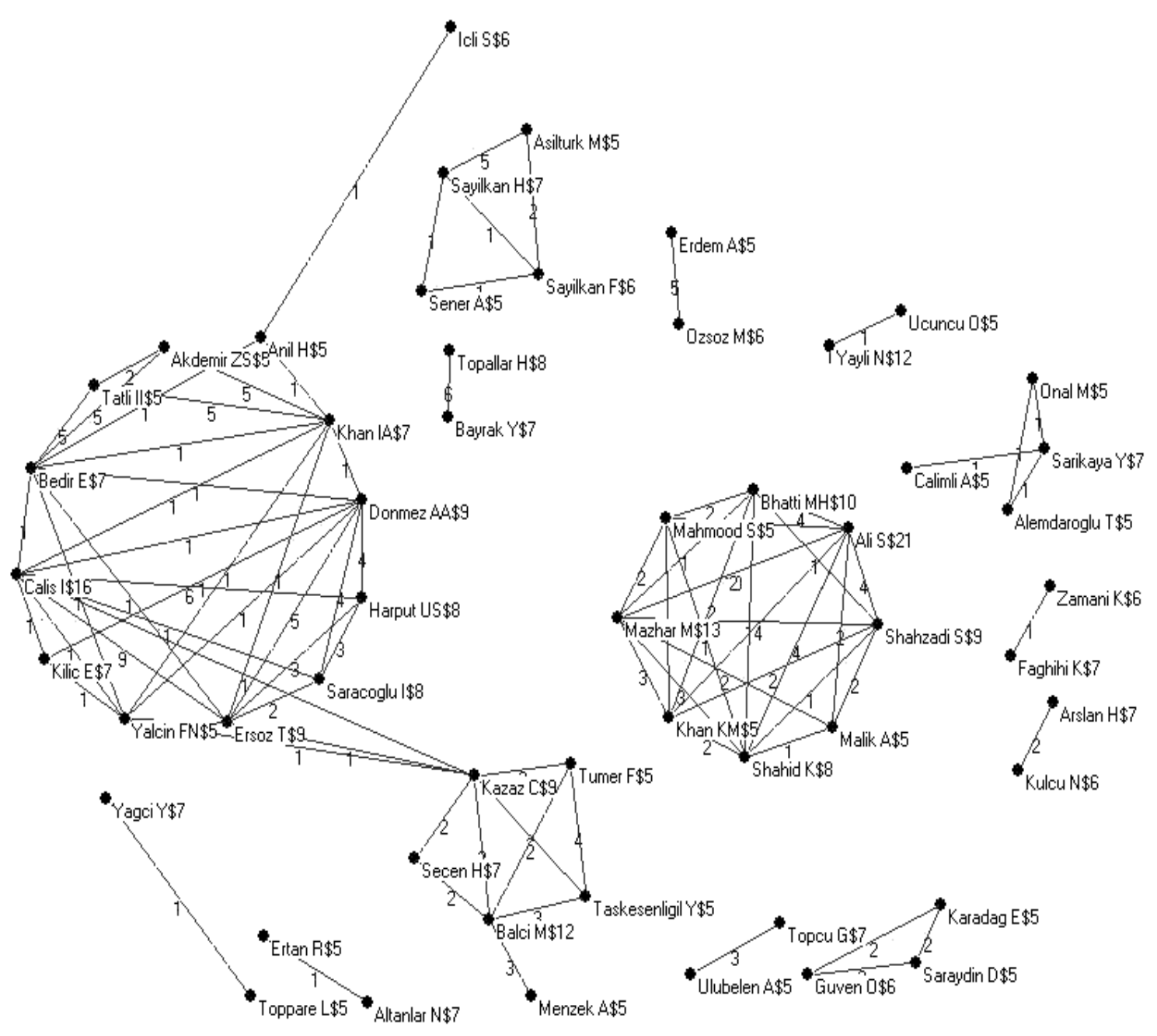

Şekil 4. Beş ve Daha Fazla Makale ile Katkıda Bulunan 54 Yazar Arasındaki İlişki

\section{Kurum}

TJC'de yayınlanan makalelerin yazarlarının 361 farklı kurumda görev yapan araştırmacılar olduğu görülmektedir. Dergide yayın yapan yazarların kurumları incelendiğinde, en çok katkının Hacettepe (86), Ankara (61), ve Atatürk (58) Üniversiteleri'ndeki araştırmacılar tarafından yapıldığı görülmektedir (Bkz. Tablo 1).

TJC'ye katkıda bulunan üniversitelerin birlikte çalışma sıklığı incelendiğinde, hernekadar farklı üniversiteler arasında belli bir işbirliği olsa dahi, üniversitelerin kendi içlerinde, yani bölümler bazında işbirliğine gittiklerini görmek mümkündür. 
Tablo 1. 10 ve Daha Fazla Makaleye Katkıda Bulunan Kurumlar

\begin{tabular}{|c|c|c|c|c|c|}
\hline $\begin{array}{l}\text { Sira } \\
\text { No }\end{array}$ & Katkı & Üniversite Adı & $\begin{array}{l}\text { Sira } \\
\text { No }\end{array}$ & Katkı & Üniversite Adı \\
\hline 1 & 86 & $\begin{array}{l}\text { Hacettepe } \\
\text { Üniversitesi }\end{array}$ & 15 & 18 & Trakya Üniversitesi \\
\hline 2 & 61 & Ankara Üniversitesi & 16 & 17 & Boğaziçi Üniversitesi \\
\hline 3 & 58 & Atatürk Üniversitesi & 17 & 16 & Dicle Üniversitesi \\
\hline 4 & 46 & ODTÜ & 18 & 13 & Mersin Üniversitesi \\
\hline 5 & 46 & Ege Üniversitesi & 19 & 13 & Çukurova Üniversitesi \\
\hline 6 & 44 & $\begin{array}{l}\text { Karadeniz Teknik } \\
\text { Üniversitesi }\end{array}$ & 20 & 12 & TÜBITAK \\
\hline 7 & 41 & Gazi Üniversitesi & 21 & 12 & Selçuk Üniversitesi \\
\hline 8 & 37 & $\begin{array}{l}\text { Quaid I Azam } \\
\text { University }\end{array}$ & 22 & 11 & Erciyes Üniversitesi \\
\hline 9 & 33 & İnönü Üniversitesi & 23 & 10 & Cumhuriyet Üniversitesi \\
\hline 10 & 30 & $\begin{array}{l}\text { İstanbul Teknik } \\
\text { Üniversitesi }\end{array}$ & 24 & 10 & Osmangazi Üniversitesi \\
\hline 11 & 27 & $\begin{array}{l}\text { Ondokuz Mayıs } \\
\text { Üniversitesi }\end{array}$ & 25 & 10 & Uludağ Üniversitesi \\
\hline 12 & 22 & İstanbul Üniversitesi & 26 & 10 & İstanbul Üniversitesi \\
\hline 13 & 22 & Universty of Karachi & 27 & 10 & Dokuz Eylül Üniversitesi \\
\hline 14 & 18 & $\begin{array}{l}\text { Yıldız Teknik } \\
\text { Üniversitesi }\end{array}$ & 28 & 10 & University of Mysore \\
\hline
\end{tabular}

TJC'de yayınlanan makalelerin \%73'ü (629) Türkiye, \%7,5’i Pakistan ve \%4,5'i Hindistan adreslidir. Dergide 52 farklı ülkeden yazar vardır. TJC'de yayınlanan makale dilinin İngilizce olması, 
onun yerel bir dergi olma özelliği taşımama olasılığını yükseltmekte ve pek çok ülke yazarının dergiye katkıda bulunuşu da, bu düşüncenin doğrulandığını ortaya koymaktadır

Kurum verileri ağ analizi yöntemi ile incelendiğinde, bir makale ile katkıda bulunan kurumların analizde, dairenin çevresinde tek bir sıra görülmekte, merkezde Hacettepe ve Atatürk Üniversitesi yer almakta, ODTÜ ise ayrı bir merkezi yapı oluştıurmaktadır. Ayrıca iki Pakistan üniversitesinin (Karachi ve Quaid'ül Azam), merkezin dışında birbiriyle ilişkili tek bir bağ ile merkeze bağlı iki ayrı yapı oluşturduğunu görmek mümkündür (Bkz. Şekil 5).

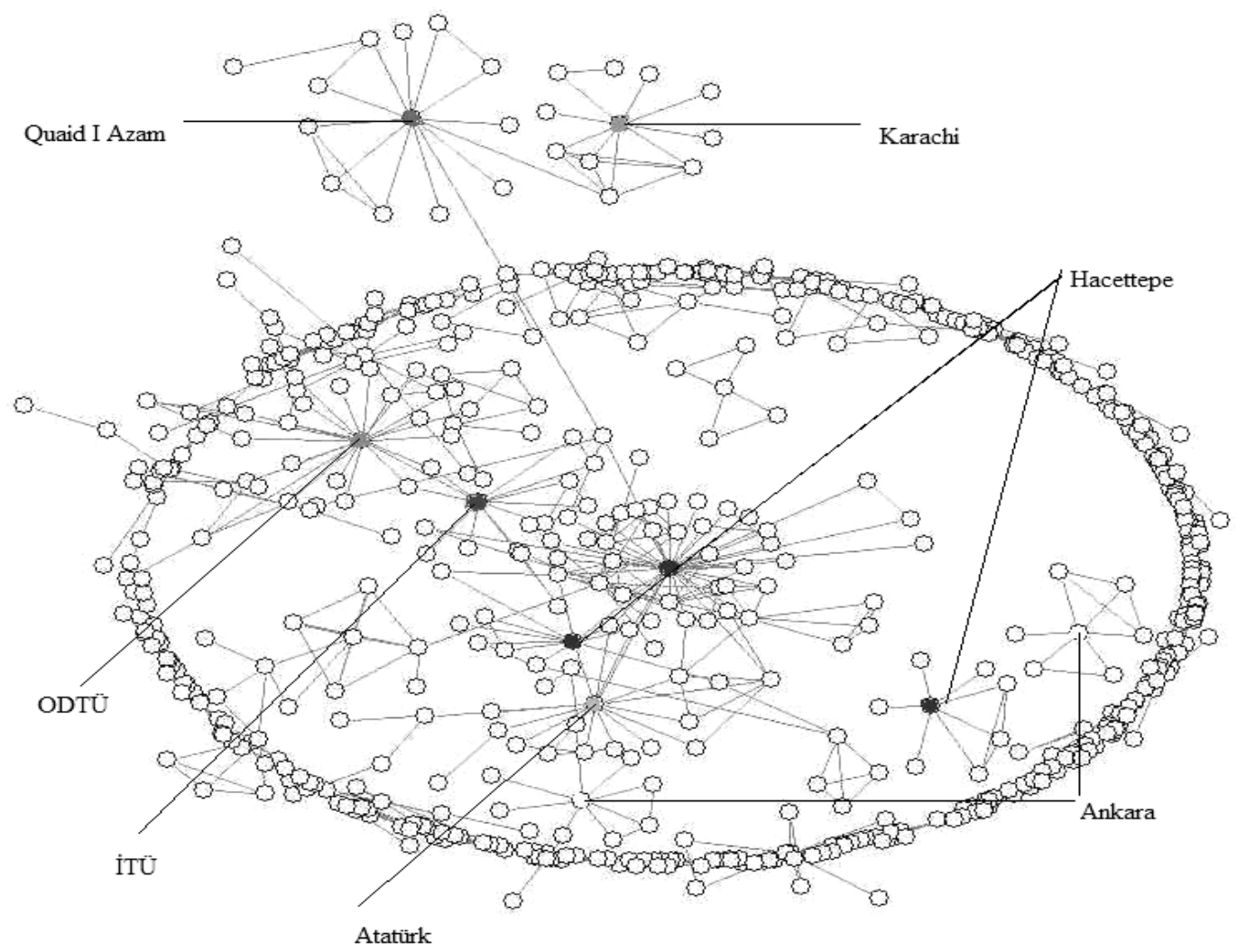

Şekil 5. Kurumlararası İletişim 
Tablo 2. TJC'de En Sık Atıf Yapılan Dergiler

\begin{tabular}{|c|c|c|}
\hline Sira No & Atıf Sayısı & Dergi Adı \\
\hline 1. & 546 & Journal of the American Chemical Society \\
\hline 2. & 356 & Phytochemistry \\
\hline 3. & 308 & Journal of Organic Chemistry \\
\hline 3. & 308 & Analitical Chemistry \\
\hline 4. & 274 & Analytica Chimica Acta \\
\hline 5. & 225 & Talanta \\
\hline 6. & 212 & Turkish Journal of Chemistry \\
\hline 7. & 187 & Tetrahedron Letters \\
\hline 8. & 176 & Tetrahedron \\
\hline 9. & 174 & Macromolecules \\
\hline 10. & 161 & Journal of Applied Polymer Science \\
\hline 11. & 152 & Analyst \\
\hline 12. & 149 & Journal of Medical Chemistry \\
\hline 13. & 143 & Journal of Physical Chemistry-US \\
\hline 14. & 140 & Inorganic Chemistry \\
\hline 15. & 128 & Synthesis and Reactivity in Inorganic Metal \\
\hline 16. & 116 & Polymer \\
\hline 17. & 111 & Chemical Review \\
\hline 18. & 109 & Journal of Electroanal Chemistry \\
\hline 19. & 107 & Journal of Organomet Chemistry \\
\hline 20. & 101 & Chemical And Pharmaceutical Bulletin \\
\hline
\end{tabular}

\section{Atıf Analizi}

1995-2007 yılları arasında TJC'de yayınlanan makalelerin kaynakçaları incelendiğinde olarak 18.482 atıfın yer aldığı görülmekte ve makale başına ortalama 21 atıf düşmektedir. Yapılan atıfların \%82'si (15.174) 2376 farklı dergiye, \%18'i (3308) dergi dışı kaynaklara yapılmıştır. Bu kaynakların en eski tarihlisi 1836 yılına aittir. Kimya alanında güncel bilgiye duyulan gereksinim gözönüne alındığında, süreli yayınların önemi bu analizden de anlaşılmaktadır. Mesela bir psikoloji dergisinde bu 
oran \%31'dir (Al ve Coştur, 2007, s. 153). En fazla kaynak gösterilen, 546 atıf ile Journal of the American Chemical Society olurken, bunu Phytochemistry ve Journal of Organic Chemistry adlı dergiler izlemektedir. Tablo 2'de 100 ve daha fazla sayıda atıf yapılan dergilerin listesi görülmektedir ve bunlar bütün dergilerdeki atıfların yaklaşık \%30'a yakın bir bölümünü oluşturmaktadırlar.

En sık atıf yapılan dergiler, etki faktörü açısından Journal of Citation Reports'da 2006 yılında disiplinlerarası Kimya konu başlığı altında incelendiğinde, atıf alanların ilk sırasındaki Journal of American Chemical Society başılıkı dergi 7,696 'lık etki faktörü ile 7. sırada yer almaktadır.

TJC'deki atıfların dergilere göre dağılımının Bradford yasasına uygunluğu test edilmiş ve yapılan bu analizde atıflar üç eşit gruba ayrılmıştır. Toplam 15.174 atıfın 5088'inin (\%33) 31, 5065'inin (\%33) 161 ve 5021'inin (\%33) 2184 dergide yayınlanan makalelere yapıldığı görülmektedir. Bradford Yasası, bu bakımdan (Garfield, 1980, s.6) TJC için de geçerli bir yasa olmuştur.

80/20 kuralı çerçevesinde de TJC'de yapılan atıflar incelenmiş ve atıfların \%80'inin (12.343), atıf yapılan dergilerin $\% 20$ 'sini (475) oluşturduğu ve bu atıfların 80/20 kuralına uyduğu saptanmıştır.

TJC'de dergilere yapılan atıfların en eskisi ise 1870 yılına aittir. Atıfların \%17'si son 10 yılda yayınlanan dergilere, \%35'i ikinci 10 yılda yayınlanan dergilere aittir (Bkz. Şekil 6). 


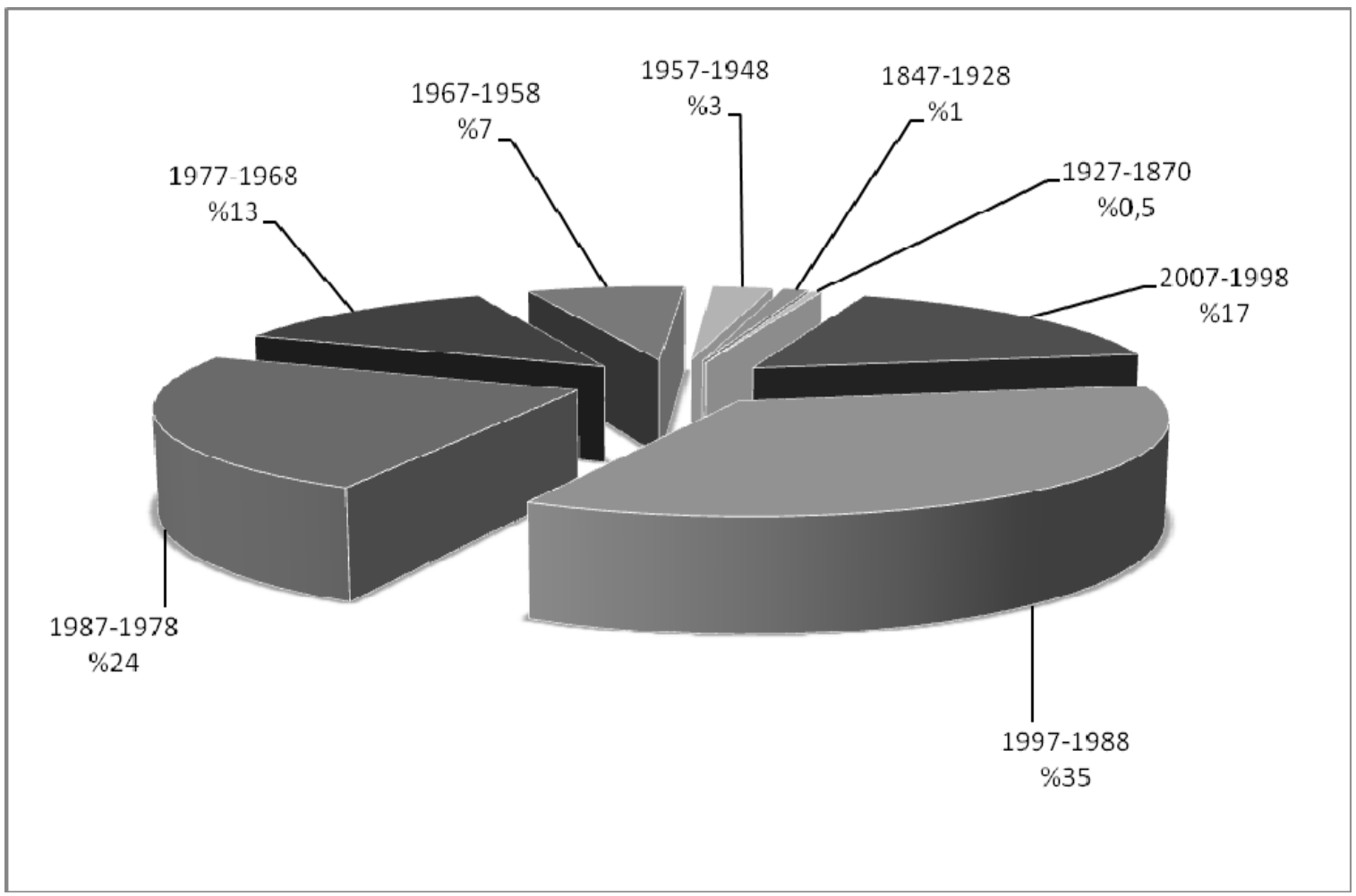

Şekil 6. Atıfların Yıllara Göre Dağılımları

\section{Journal Citation Reports'ta TJC'nin Yeri}

Dergilere yönelik olarak etki faktörü, o yıl içinde alınan atıfların, önceki iki yılda yayınlanan makale sayısına bölünmesiyle hesaplanır (Impact, 2007). SCl'da TJC, dâhil olduğu disiplinlerarası Kimya konu başlığında 2005 yılında en yüksek etki faktörü olan 0,698 'e ulaşarak 125 dergi arasında 79. olmuştur. Kimya mühendisliği alanında ise 116 dergi arasından 56. sırada yer almıştır. Vinkler (1999, s.632) Kimya dergisi yazarlarının etki faktörü yüksek dergilere atıf yaptığını ifade eder. 2006 yılına kadar etki faktörünü istikrarlı bir şekilde yükselten TJC bu yükselişini 2006 yılında sürdürememiş disiplinlerarası Kimya konu başlığında 124 dergi arasından 86. sıraya, Kimya Mühendisliği alanında ise 110 dergi içinde son sıraya gerilemiştir. Fakat yine de TJC'nin indekslenmeye başladığı 1995 yılından itibaren etki faktörünü yaklaşık 0,7'ye kadar yükseltmesinin, Kimya dergileri arasında Türkiye için bir başarı olduğu ifade edilmelidir. TJC'nin etki faktörünün yıllara göre gelişimi, Şekil 7'de verilmiştir. 


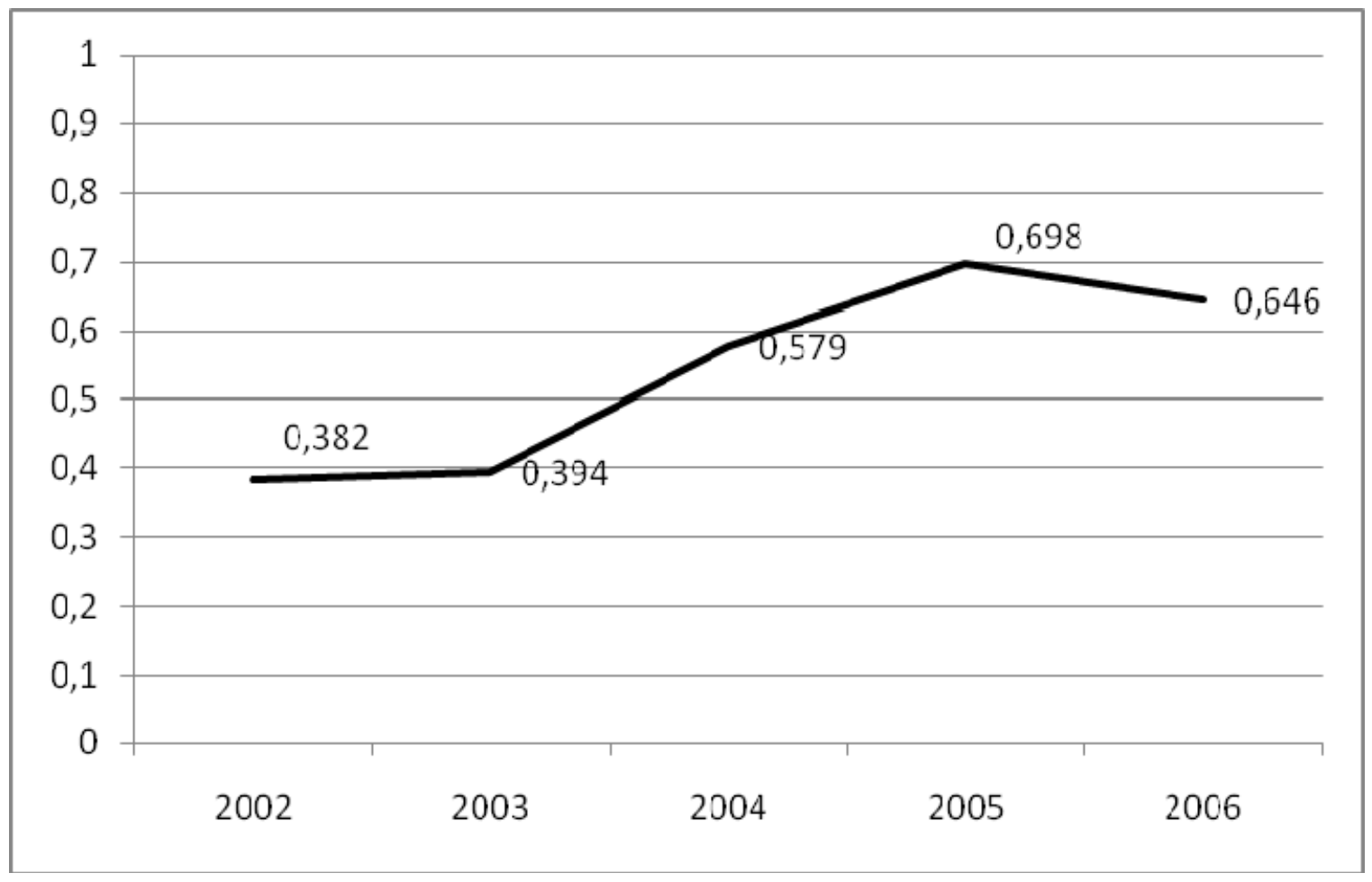

Şekil 7. TJC'nin Etki Faktörünün Yıllara Göre Gelişimi

\section{TJC'ye Yapılan Atıflar}

TJC'de yayınlanan 861 makaleden \%39'u (337) atıf almamıştır. Geri kalan \%61'lik (524) kısım ise kendine atıf dışında toplam 1523 atıf almıştır. En çok atıf yapılan bir makale $32 \mathrm{kez}$ atıf almış, makale başına ise ortalama 2,19 atıf alınmıştır. Şekil 8'de TJC'deki makalelerin yıllara göre aldıkları toplam atıf sayılarının dağılımları verilmektedir. TJC'de yayınlanan bu makalelere yapılan atıfların \%47'sini Türkiye adresli, \%9'unu ABD ve \% 8'ini Hindistan başta olmak üzere 85 farklı ülkeden araştırmacılar oluşturmaktadır. Derginin İngilizce yayınlanması sebebiyle en çok atıf aldığı kaynakların dillerine bakıldığında \%98 ile İngilizce ilk sıradadır. Az sayıda yayın dili Portekizce $(\% 0,4)$, Romence $(\% 0,4)$ Fransızca $(\% 0,3)$, Çince $(\% 0,1)$, Çekçe $(\% 0,1)$, Rusça $(\% 0,1)$ ve Almanca $(\% 0,05)$ olan yayınlardan da atıf almıştır. 


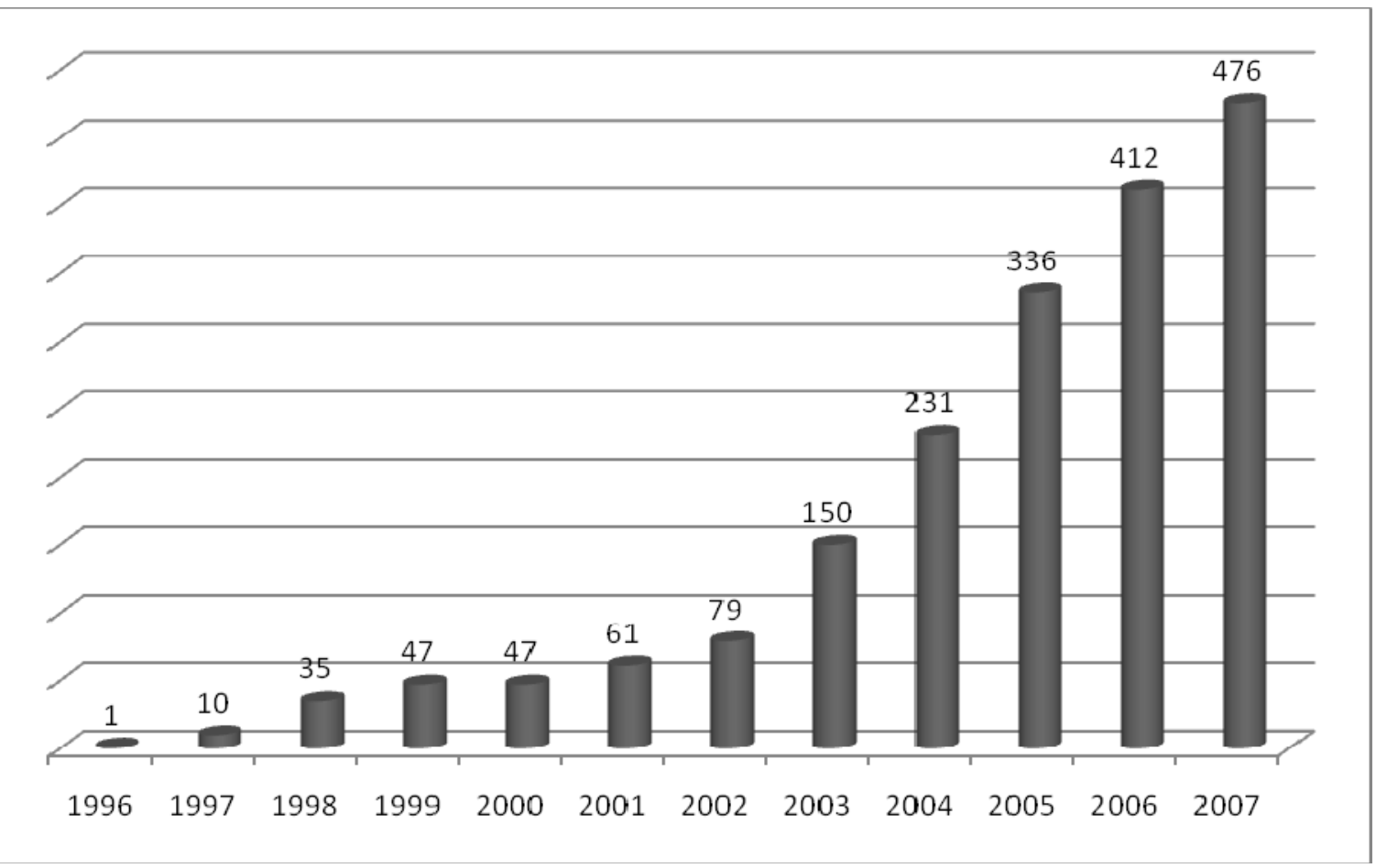

Şekil 8. TJC'deki Makalelerin Yıllara Göre Aldıkları Atıf Sayıları

TJC'de yayınlanan makalelere yapılan 1429 atıf 450 farklı dergideki makalelerden gelmektedir. TJC dışında en sık atıf aldığı dergi Acta Crystallographica Section E-Structure Reports Online olmuştur (Bkz. Tablo 3).

TJC'de yayınlanan makalelerde en sık atıf yapılan ve 7,696 etki faktörü ile 7. sırada bulunan Journal of the American Chemical Society dergisinden ise yalnız 3 atıf almıştır. TJC'de en sık atıf alan diğer iki dergiden Phytochemistry $8 \mathrm{kez}$, Journal of Organic Chemistry ise TJC'ye 9 kez TJC'ye atıf yapmıştır. TJC'ye atıf yapan dergilerin JCR'daki etki faktörleri ve ait oldukları disiplinlerdeki sıralamaları incelendiğinde birinci sıradaki Acta Crystallographica Section E 0,567 etki faktörü ile 20. sırada, Asian Journal of Chemistry 0,173 etki faktörü ile 121. sırada, Journal of Applied Polymer Science 1,306 etki faktörü ile 29. sırada Journal of Hazardous Materials 1,855 etki faktörü ile 7. sırada ve Talanta 2,810 etki faktörü ile 11. sırada yer almaktadır. 
Tablo 3. TJC'ye En Sık Atıf Yapan Dergiler

\begin{tabular}{|c|c|c|}
\hline Sıra No & Atıf Sayısı & Dergi Adı \\
\hline 1 & 113 & Turkish Journal of Chemistry \\
\hline 2 & 51 & $\begin{array}{l}\text { Acta Crystallographica Section E-Structure Reports } \\
\text { Online }\end{array}$ \\
\hline 3 & 41 & Asian Journal of Chemistry \\
\hline 3 & 41 & Journal of Applied Polymer Science \\
\hline 4 & 27 & Journal of Hazardous Materials \\
\hline 5 & 23 & Talanta \\
\hline 6 & 22 & Journal of The Chemical Society of Pakistan \\
\hline 7 & 20 & Analytical Letters \\
\hline 8 & 16 & Journal of Chemical Research-S \\
\hline 8 & 16 & Analytica Chimica Acta \\
\hline 9 & 15 & Tetrahedron \\
\hline 10 & 13 & Dyes And Pigments \\
\hline 10 & 13 & Molecules \\
\hline 10 & 13 & Polymer Bulletin \\
\hline 10 & 13 & Journal of Colloid And Interface Science \\
\hline 11 & 12 & Fresenius Environmental Bulletin \\
\hline 11 & 12 & Russian Journal of Coordination Chemistry \\
\hline 11 & 12 & Transition Metal Chemistry \\
\hline 12 & 11 & Polymer \\
\hline 13 & 10 & Biochemical Systematics And Ecology \\
\hline 13 & 10 & Journal of Coordination Chemistry \\
\hline 13 & 10 & $\begin{array}{l}\text { Synthesis \& Reactivity in Inorganic \& Metal-Organic } \\
\text { Chemistry }\end{array}$ \\
\hline
\end{tabular}




\section{Kimya Alanında Üzerinde Çok Çalışılan Konular}

"Ülkemizde kimya alanındaki öncelikli araştırma konuları nelerdir?" sorusuna cevap bulabilmek amacıyla TJC'de makale isimlerindeki en sık geçen sözcükleri saptamak için bir analiz yapılmış ve new, studies, study, investigation, characterization gibi Kimya alanındaki araştırma konuları hakkında fikir vermeyen sözcüklerin ilk 20 kelime içinde önemli bir yer tuttuğu görülmüştür (Bkz. Tablo 4).

Tablo 4. Makale Adlarında Geçiş Sıklıklarına Göre Sözcüklerin Dağılımı

\begin{tabular}{|c|c|c|}
\hline Sira No & Sözcük & $\begin{array}{l}\text { Geçiş Sıklığı } \\
\text { Geçiş Sıklığı }\end{array}$ \\
\hline 1 & Synthesis & 176 \\
\hline 2 & Determination & 106 \\
\hline 3 & Acid & 81 \\
\hline 4 & Derivatives & 72 \\
\hline 5 & Characterization & 69 \\
\hline 6 & New & 55 \\
\hline 6 & Complexes & 55 \\
\hline 7 & Studies & 46 \\
\hline 8 & Investigation & 36 \\
\hline 9 & Properties & 33 \\
\hline 10 & Effect & 32 \\
\hline 11 & Spectrophotometric & 32 \\
\hline 11 & Activity & 31 \\
\hline 12 & Metal & 31 \\
\hline 12 & Study & 29 \\
\hline 13 & Adsorption & 28 \\
\hline 14 & Novel & 27 \\
\hline 15 & Extraction & 26 \\
\hline 16 & Kinetics & 26 \\
\hline 16 & Aqueous & 25 \\
\hline
\end{tabular}

"Stop wordlist kullanılmıştır. 
Makale adlarında birlikte geçen kelimeler analiz edildiğinde ise Synthesis ve Characterization sözcüklerinin makale adlarında 46 kez birarada geçtiği görülmüştür (Bkz.Tablo 5).

Tablo 5. Makale Adlarındaki Sözcüklerin Birlikte Geçme Sıkığı๋

\begin{tabular}{|lll|}
\hline Sözcük & Sözcük & $\begin{array}{l}\text { Birlikte Geçme } \\
\text { Sıklığ }\end{array}$ \\
\hline Synthesis 176 & Characterization 69 & 46 \\
\hline Synthesis 176 & Derivatives 72 & 38 \\
\hline Synthesis 176 & New 55 & 30 \\
\hline Synthesis 176 & Complexes 55 & 28 \\
\hline Spectrophotometric 32 & Determination 106 & 22 \\
\hline Synthesis 176 & Activity 31 & 18 \\
\hline Synthesis 176 & Antimicrobial 18 & 15 \\
\hline Crystal 16 & Structure 23 & 15 \\
\hline Synthesis 176 & Novel 27 & 13 \\
\hline New 55 & Derivatives 72 & 13 \\
\hline Synthesis 176 & Acid 81 & 13 \\
\hline Characterization 69 & Complexes 55 & 13 \\
\hline Synthesis 176 & Spectral 14 & 12 \\
\hline Atomic 13 & Absorption 12 & 11 \\
\hline Synthesis 176 & Spectroscopic 23 & 11 \\
\hline Organotin(IV 11 & Derivatives 72 & 10 \\
\hline Synthesis 176 & Activities 18 & 10 \\
\hline Determination 106 & Acid 81 & 10 \\
\hline Synthesis 176 & Biological 16 & 10 \\
\hline Aqueous 25 & Solution 22 & 10 \\
\hline
\end{tabular}

"Stop wordlist kullanılmıştır. 


\section{Sonuç ve Öneriler}

1995-2007 yılları arasında TJC'de 861 makale yayınlanmış, makelelere 1628 farklı yazar ve 361 farklı kurum katkıda bulunmuştur. Makale başına düşen ortalama yazar sayısı 1,9 iken en çok katkıda bulunan kurumlar Hacettepe, Ankara ve Atatürk üniversiteleri olmuştur. Ortak yazarlılıkta öncelikle kurumiçi yani bölümlerarası çalışmalar yaygınken, kurumlararası yani üniversitelerarası çalışmalar da görülmeye başlamıştır. Yazarlar ortak çalışma açısından incelendiğinde, Pakistan adresli araştırmacılar küçük bir grup oluştururken, Türkiye adresli araştırmacıların daha büyük bir grup oluşturmakta oldukları gözlenmiştir. Yazarların dağılım özellikleri, Price ve Lotka Yasası'na ve 80/20 Kurali'na uymamaktadır. TJC'de yayınlanan makalelerde toplam olarak 18.482 kaynağa atıf yapılmış, makale başına ortalama ise 21 olmuştur. Atıfların \%82'si dergilere \%18'i dergi dışı kaynaklara yapılmış ve en sık atıf Journal of the American Chemical Society Adlı dergiye yönelmiştir. TJC'de yapılan atıflar Bradford Yasası ve 80/20 Kuralı'na uymaktadır. TJC'ye yapılan atıflar incelendiğinde makalelerin \%61'inin atıf aldığı ve bu rakamın yıllara göre bir artış eğiliminde olduğu saptanmıştır. En sık atıf gösterilen dergiler sırasıyla TJC, Acta Crystallographica Section E-Structure Reports Online, Asian Journal of Chemistry ve Journal of Applied Polimer Science olmuştur. TJC SCl'de indesklenmeye başladığı yıldan itibaren etki faktörünü istikrarlı bir biçimde sürdürerek 0,7'ye kadar yükseltmiştir.

Kimya alanında yapılan bu bibliyometrik çalışma ile bu konuda yayın yapan yazarlar daha iyi tanınarak, sözkonusu bilim dalındaki gelişme gözlenebilir. Kimya alanında ülkemizde yayınlanan tek hakemli dergi olan TJC'nin bibliyometrik analizinden elde edilen bulgular doğrultusunda üniversite ve araştırma kütüphaneleri özellikle dergi koleksiyonlarını gözden geçirebilir ve çekirdek dergi koleksiyonları oluşturabilirler. Kimya alanındaki bilimsel iletişimin ortaya çıkarılabilmesi ve geliştirilebilmesi, ISI kapsamına giren bu konudaki Türkiye adresli yayınların ayrıntılı bir şekilde analiz edilmesiyle gerçekleşebilir. 


\section{Kaynakça}

Al, U. (2005). Çok yazarlıı̆ın bilimsel iletişimdeki yeri. Prof. Dr. Nilüfer Tuncer'e Armağan içinde (ss. 31-41). Mehmet Emin Küçük (Yay. haz.). Ankara: Türk Kütüphaneciler Derneği. 15 Kasım 2007 tarihinde http://yunus.hacettepe.edu.tr/ umutal/ publications/multipleauthorship.pdf adresinden erişildi.

Al, U ve Coştur, R. (2007). Türk Psikoloji Dergisi'nin Bibliyometrik Profili. Türk Kütüphaneciliği, 21, (2), 142-163. 15 Kasım 2007 tarihinde http://www.kutuphaneci.org.tr/web/node.php?action=6 \&type $=6 \&$ target $=$ contentShow\&id=2143\&node_id=412 adresinden erişildi.

Egghe L. ve Rousseau, R. (1990). Introduction to Informetrics quantitative methods in library, documentation and information science. Elsevier Science Publication Netherland. 1 Kasım 2007 tarihinde http://eprints.rclis.org/archive/00003297/ adresinden erişildi.

Egghe, L. (1986). On the 80/20 Rule. Scientometrics, 10, (1-2), 55-68.

Garfield, E. (1972). Citation analysis as a tool in journal evaluation. Science, 178, 471-479. 15 Kasım 2007 tarihinde JSTOR veri tabanından erişildi.

Garfield, E. (1980) Bradford's Law and related statistical pattern. Current Contents, 19, 5-12. 15 Kasım 2007 tarihinde http://www.garfield.library.upenn.edu/essays/v4p476y197980.pdf adresinden erişildi.

Impact factor. (2007). 15 Kasım 2007 tarihinde http://scientific.thomson.com/free/essays/journalcitationreports/i mpactfactor/ adresinden erişildi

Liu, Z. (2003). "Trends in transforming scholarly communication and their implications", Information Processing \& Management 39(6):889-898.

Lotka, A.J. (1926). The frequency distribution of scientific productivity. Journal of the Washington Academy of Sciences, 16, 317-323. 
Pritchard, A. (1969). Statistical bibliography or bibliometrics? Journal of Documentation, 25, 348-349.

Rowlands, I. (2005). Emerald authorship data, Lotka's law and research productivity. Aslib Proceedings: New Information Perspectives, 57, (1), 5-10.

Said, Y.H., Wegman, E.J., Sharabati, W. K ve Rigsby, J.T. (2008). Social network of author-coauthor relationships. Computational Statistics and Data Analysis, 52, 2177-2184.

Subramanyam, K. (1979). Scattering, Laws of. In Encyclopedia of Library and Information Science, 26, 336-354. Ed. Allen Kent. New York: Marcel Dekker.

Yılmaz, M (2005). 80/20 Kuralı. Türk Kütüphaneciliği, 19, (3), 308320. 15 Kasım 2007 tarihinde http://www.kutuphaneci.org.tr/ web/node. php?action $=6 \&$ type $=6 \&$ target $=$ contentShow $\&$ id $=1482$ \&node_id=198 adresinden erişildi.

Yurtsever, E. ve Gülgöz, S. (1999). The increase in the rate of publications originating from Turkey. Scientometrics, 46, (2), 321-336. 